entre os dois radionuclidos o que acontece ao fim de c. 500 mil anos (k.a.). A medição daquela razão na calcite permite, portanto, determinar a data da sua formação. Fazendo uso da espectrome- tria de massa, os limites de aplicação do método são 1 k.a. - 500 k.a..

Ultimamente, o método do ${ }^{234} \mathrm{U} /{ }^{230} \mathrm{Th}$ tem sido também usado na construção da curva de calibração de datas de ${ }^{14} \mathrm{C}$ desde o limite permitido pela dendrocronologia (11,9 k.a. BP) até c. 40 k.a. BP. Para isso, tem-se recorrido a corais com idades maiores que o referido limite, aos quais se aplicam ambos os métodos de datação.

\title{
O Urânio na Mundovisão Científica
}

\section{Introdução}

Embora reconhecendo toda a importância científica da descoberta dos raios $X$ (em Novembro de 1986, por Wilhelm Conrad Roentgen) talvez não se exagere dizendo que a sua consequência mais importante foi, ainda que inviamente, a descoberta (em Fevereiro de 1896, por Henri Becquerel) da radioactividade. E tudo se deveu à maneira como Roentgen cuidou da sua glória enviando para cientistas estrategicamente colocados na Europa notícias do seu trabalho com imagens obtidas com a "nova espécie de raios". Assim, na Academia das Ciências de Paris, Poincaré apresenta o trabalho. $\mathrm{O}$ que aconteceu depois continua em muitas narrações mal contado Parece, com efeito, que não foi uma sugestão de Poincaré mas de um dos assistentes, Becquerel, que relacionou a fluorescência no tubo de Crookes emissor dos novos raios com a produção destes. De todas as formas, o elemento de serendipity na descoberta tem sido exagerado ainda que a selecção de sais de urânio se devesse à casualidade do interesse de gerações da família Becquerel pois que já o avô de Henri tinha mostrado que a fluorescência dos sais de urânio era intensa em sais urânicos e nula em sais uranosos, o que virá a ter uma importância óbvia na descoberta. Verdadeiramente, a serendipity intervem no episódio final quando o sal duplo de urânio e potássio foi colocado sobre uma lâmina de cobre em forma de cruz de Malta, com a espessura de dois milímetros, sobreposta a uma chapa fotográfica protegida da luz por um papel espesso, ficou dentro de um gaveta dias seguidos, por falta de Sol para excitar a fluorescência e, mesmo assim, Becquerel ter revelado a chapa. Desta forma, o urânio fica ligado não por si mesmo mas, como se veria depois, pela sua descendência, à descoberta da radioactividade, nome dado ao fenómeno por Marie Curie, anos depois. Como é óbvio, não foram as radiações do urânio as responsáveis pela exposição da película. Com efeito, os raios que emitia o urânio não ultrapassavam mais do que 0,004 milimetros de alumínio. É difícil dizer quem verdadeiramente descobriu a radioactividade do urânio (melhor, dos urânios) ainda que o meu candidato seja Ernest Rurherford, em 1898, com as suas experiências sobre a absorção das radiações do urânio em lâminas de alumínio, onde se revelou a presença de raios a que chamou raios alfa. A Becquerel se devem estudos iniciais que iriam balizar o caminho de muitas descobertas futuras. Já com um electroscó- pio, e não com chapas fotográficas mostra que a temperatura ( $\mathrm{de}-180^{\circ} \mathrm{C}$ a $80^{\circ} \mathrm{C}$ ) não influi na radioactividade da amostra do sal de urânio (mais um dos muitos casos em que a insensibilidade dos instrumentos facilitou o progresso inicial do estudo científico). Seguindo essa radioactividade durante quatro anos conclui pela persistência do fenómeno com a mesma intensidade (outro caso de insensibilidade favorável). É aqui que se questiona o "princípio da conservação da energia", que é imprudente ignorar como muitos físicos aprenderam duramente à sua custa. Seguem-se os estudos da proveniência da energia que "alimentava a radioactividade" ( Da luz? Do ar? Do vácuo?) que mostra que a fantasia não é apenas privilégio dos criadores literários a quem infelizmente (ou talvez não), falta a "polícia" da experiência para os encaminhar para a "verdade", a que se chama científica. Esquece-se muitas vezes que se deve a Becquerel, principalmente, o reconhecimento de que os raios catódicos eram electrões (descobertos oficialmente por J. J. Thomson em 1898), e que os electrões eram uma das partículas emitidas por alguns elementos radioactivos (os raios beta de Rutherford). Os raios gama, os responsáveis verdadeiros pela descoberta da radioactivida- 
de, foram só "descobertos" por P .Villard em 1900. O conceito de isótopos é estabelecido em 1913 (o meu candidato é Fajans), pela revelação da existência de mais do que uma espécie de chumbo como produto final das séries radioactivas então conhecidas além da do urânio. Nessa altura havia já, perturbadoramente, dezenas de candidatos a poucos lugares na Tabela Periódica de Mendeleev. O conceito de semi-vida (ou periodo de semi-transformação) é estabelecido por Rutherford em 1904, e mostra ser uma característica fundamental dos elementos radioactivos (a que se chamariam radionúclidos, em 1950) independente da pressão, da temperatura ou das ligações químicas dos elementos (em geral). Brevemente se recordam os padrões fundamentais erguidos por esses estudos, desde a descoberta do núcleo atómico e sua constituição por neutrões e protões que inicia um dos ramos científicos mais vigorosos do nosso tempo, a física das partículas. Assim, a teoria da relatividade (de 1905 e 1915) e a mecânica quântica (de 1899-1900 e cerca de 1930) as duas balizas da física moderna, encontram aqui o seu terreno natural. Brevemente se refere a energia nuclear (vislumbrada logo pelos Curie quando faziam ferver água com rádio nela mergulhado) e a energia de fusão. Acentua-se a importância da radioactividade e das reacções nucleares no problema da existência na Terra de um meio favorável à vida e na explicação da energia das estrelas, em especial a luz emitida pelo Sol, o grande reactor nuclear do Sistema Solar. Num outro trabalho foi relatado o papel dos radionúclidos, em particular do urânio, na datação em geral. Continuam a ter uma importância particular nos problemas cosmológicos, como notou George Gamow quando, na década de 1940 considerou, pela primeira vez cientificamente, a criação do Universo e seu desenvolvimento. Eis um dos seus primeiros raciocínios, com números actualizados sobre as semividas.

Conhecendo-se a secção eficaz dos neutrões rápidos para o urânio é natural supôr que todos os isótopos do urânio tivessem sido formados ao mesmo tempo. Desta forma, tanto o urânio 238 (semi-vida $4,51 \times 10^{9}$ a) como o o urânio $235\left(7,1 \times 10^{8}\right.$ a) foram formados ao mesmo tempo numa supernova (o que Gamow não sabia mas que aqui não importa). Assim designando por $U_{5} 0$ urânio 235 e por $\cup_{8}$ o urânio 238 e por $\mathrm{N}$ o número original de átomos de ambos os isótopos:

$$
\begin{aligned}
& U_{8}=N e^{-(0,693 / T 8) \Delta t} \\
& U_{5}=N e^{-(0.693 / T 5) \Delta t}
\end{aligned}
$$

Donde

$$
\begin{aligned}
& \cup_{8} / U_{5}=139=\mathrm{e}^{((0,693 / T 5)-(0,693 / \mathrm{T} 8) / \Delta t} \\
& \Delta \mathrm{t}=\ln 139 /(0,693 / T 5)-(0,693 / T 8) \\
& \Delta \mathrm{t}=\mathbf{6} \times 10^{9} \mathbf{a}
\end{aligned}
$$

Assim, a data da formação do "nosso" sistema solar a partir da explosāo de uma supernova é superior a este valor (a Terra formou-se há cerca de 4,6 mil milhões de anos) e os elementos químicos do nosso corpo, por exemplo, foram criados nessa supernova. Mais recentemente, R.Cayret et al. (Measurements of Stellar Age from Uranium Decay, Nature, 438, 691-2, 2001) conseguiram, pela primeira vez, numa estrela galáctica detectar no espectro óptico radiações emitidas por estados excitados do urânio 238 e calcular a sua abundância relativa a outros elementos. Anteriormente apenas se tinham detectado riscas do Th 232 (semi-vida 14 Ga). Durante a vida do Universo, a radioactividade do Th 232 ter-se-ia reduzido apenas a metade. Neste particular, a semi-vida do urânio 238 (semi-vida 4,51 Ga) será muito mais conveniente para uma datação. Admite-se que todos os elementos pesados foram formados num pequeno intervalo de tempo nos primeiros tempos da história da Galáxia. Se $T h_{\text {obs }}$ e $T h_{0}$ forem as quantidades observadas (obs) e originais (o) (abundâncias relativas) do Th 232 quando este se formou, e $U_{o b s}$ e $U_{0}$, essas quantidades para o urânio 238, teremos

$$
\begin{aligned}
& T h_{o b s}=T h_{0} e^{-\lambda} T h^{\Delta t} \\
& U_{o b s}=U_{0} e^{-\lambda U^{\Delta t}}
\end{aligned}
$$

e

$$
(T h / U)_{o b s}=(T h / U)_{0} e^{\left(\lambda_{U}-\lambda_{T h}\right) \Delta t}
$$

Se $r$ fôr a abundância relativa de um elemento estável com números atómicos próximos do urânio e tório, como o ósmio (Os) e o irídio (Ir), com riscas visíveis no espectro óptico da mesma estrela, pode-se escrever

$$
\begin{aligned}
& \Delta t=21,8\left[\log (\mathrm{U} / \mathrm{Th})_{0}-\log (\mathrm{U} / \mathrm{Th})_{\mathrm{obs}}\right] \mathrm{Ga} \\
& \Delta \mathrm{t}=46\left[\log (\mathrm{Th} / \mathrm{r})_{0}-\log (\mathrm{Th} / \mathrm{r})_{\mathrm{obs}}\right] \mathrm{Ga} \\
& \Delta \mathrm{t}=14\left[\log (\mathrm{U} / \mathrm{r})_{0}-\log (\mathrm{U} / \mathrm{r})_{\text {obs }}\right] \mathrm{Ga}
\end{aligned}
$$

Claro que os valores das abundâncias relativas iniciais dependem do conhecimento teórico dos processos de nucleosíntese e de se supor que serão os mesmos na estrela e no Sistema Solar.

Os resultados finais obtidos foram (trabalho citado) (ver tabela)

\section{Valor Médio $=12,5 \mathrm{Ga}$}

\section{Idade da Galáxia $12,5+(0,1-0,3) \mathrm{Ga}$}

(A Idade do Universo tem de ser superior, evidentemente)

\section{Tabela}

Idades derivadas para o Cs31082-001 em função das taxas de produção dos elementos

Par de elementos log (taxa de prod.) log (relação obs.) Idade calculada (Ga)

\begin{tabular}{cccc}
\hline U/Th & $-0,258$ & $-0,74 \pm 0,15$ & $10,6 \pm 3,3$ \\
\hline U/Th & $-0,10$ & $-0,74 \pm 0,15$ & $14,0 \pm 3,3$ \\
\hline U/Os & $-1,27$ & $-2,19 \pm 0,18$ & $3,6 \pm 2,7$ \\
\hline U/lr & $-1,30$ & $-2,10 \pm 0,17$ & $11,8 \pm 2,5$ \\
\hline
\end{tabular}

